\title{
Avaliação da ocorrência de anticorpos anti-Toxoplasma gondii, em soros de caprinos do estado de São Paulo, e associação com variáveis epidemiológicas, problemas reprodutivos e riscos à saúde pública ${ }^{1}$
}

\author{
José R. Modolo ${ }^{*}$, Hélio Langoni ${ }^{2}$, Carlos R. Padovani ${ }^{3}$ Ligia V. Barrozo ${ }^{3}$,
} Bárbara L.S. Leite ${ }^{2}$, Solange M. Gennari ${ }^{4}$ e Anee V.M. Stachissini ${ }^{2}$

\begin{abstract}
Modolo J.R., Langoni H., Padovani C.R., Barrozo L.V., Leite B.L.S., Gennari S.M. \& Stachissini A.V.M. 2009.[Occurrence of anti-Toxoplasma gondii antibodies in goat sera in the state of São Paulo, and its association with epidemiological variables, reproductive problems and risks on public health.] Avaliação da ocorrência de anticorpos anti-Toxoplasma gondii, em soros de caprinos do estado de São Paulo, e associação com variáveis epidemiológicas, problemas reprodutivos e riscos à saúde pública. Pesquisa Veterinária Brasileira 28(12):606-610. Faculdade de Medicina Veterinária e Zootecnia, Universidade Estadual Paulista, Cx. Postal 524, Botucatu, SP 18618-000, SP, Brazil. E-mail: jrmodolo@ fmvz.unesp.br

The study evaluated the anti-Toxplasma gondii antibodies occurrence in dairy goats in São Paulo State, and also verified likely associations with age, sex, presence of cats, occurrence of reproductive problems, and potential risks to public health. Serum was obtained from 923 animals of both sex, over three months of age from 17 properties in different cities. For the diagnosis, the indirect immunofluorescence reaction (RIFle"16) and a questionnaire about health to collect epidemiological information and the reproductive cycle of every goat were used. Among all properties, 15 foci of $T$. gondii were diagnosed with seropositivity ranging from $2.70 \%$ to $81.25 \%$. Neither association between the frequency of seropositivity and the sex of animals nor occurrence of reproduction failure of goats was identified. There was positive influence of anti- $T$. gondii antibody rate due to the older age of the animals and the presence of cats in pens. The risk of transmitting $T$. gondii to the public health must be considered, once in some properties where the positive serology was verified natural, products such as milk and/or meat are commercialized. Results were discussed at $5 \%$ level of significance.
\end{abstract}

INDEX TERMS: Toxoplasma gondii, occurrence, commercialization, map distribution, dairy goats.

\footnotetext{
${ }^{1}$ Recebido em 3 de outubro de 2007.

Aceito para publicação em 16 de julho de 2008.

Suporte financeiro da Fundação para o Desenvolvimento da Universidade Estadual Paulista (Fundunesp)

${ }^{2}$ Faculdade de Medicina Veterinária e Zootecnia, Universidade Estadual Paulista (Unesp), Cx. Postal 524, Botucatu, SP 18618-000, Brasil.

*Autor para correspondência: jrmodolo@fmvz.unesp.br

${ }^{3}$ Instituto de Biociências, Unesp, Botucatu, SP 18618-000.

${ }^{4}$ Faculdade de Medicina Veterinária e Zootecnia, Universidade de São Paulo (USP), Av. Prof. Dr. Orlando Marques de Paiva 87, São Paulo, SP 05508-270, Brasil.
}

RESUMO.- Objetivando avaliar a ocorrência de anticorpos anti-Toxoplasma gondii, em caprinos leiteiros do estado de São Paulo, e verificar possíveis associações com idade, sexo, presença de gatos, problemas reprodutivos e potenciais riscos à saúde pública, foram considerados soros de 923 caprinos, de ambos os sexos e idade acima de três meses, provenientes de 17 propriedades de diferentes municípios. Para o diagnóstico, utilizou-se a reação de imunofluorescência indireta (RIFle"16) e, também, um inquérito sobre saúde, a fim de se coletarem informações epidemiológicas e de esfera reprodutiva de todos os 
capris. Os resultados foram discutidos no nível de $5 \%$ de significância. Do total das 17 propriedades, foram diagnosticados 15 focos de $T$. gondii, com positividade entre $2,70 \%$ e $81,25 \%$. Não foram verificadas associações entre freqüência de soropositividade e sexo dos animais nem ocorrência de falhas reprodutivas, nos capris. Constatouse influência positiva na taxa de anticorpos anti- $T$. gondii pelo aumento da idade dos caprinos e presença de gatos, nos capris. Além de a enfermidade encontrar-se amplamente difundida no estado de São Paulo, o risco eminente de transmissão de $T$. gondii à saúde pública também deve ser considerado, uma vez que se encontraram focos onde se comercializavam produtos "in natura", como leite e carne.

TERMOS DE INDEXAÇÃO: Toxoplasma gondii, ocorrência, comercialização, mapeamento, caprinos leiteiros.

\section{INTRODUÇÃO}

A infecção por Toxoplasma gondii é comum nos pequenos ruminantes (Dubey \& Kirkbride 1989) e, entre os animais de produção, os caprinos são os mais seriamente afetados, causando graves prejuízos aos produtores (Dubey \& Adams 1990, Engeland et al. 1996). No Brasil, já foram realizados diversos estudos verificando a alta prevalência de anticorpos anti- $T$. gondii, na espécie caprina (Araújo et al. 1984, Chiari et al. 1987; Sella et al. 1994, Mainardi et al. 2003, Meireles et al. 2003, Silva et al. 2003, Figliuolo et al. 2004). Esse agente tem como hospedeiros definitivos membros da família Felidae, entre os quais, gatos domésticos, que apresentam importante papel na epidemiologia da toxoplasmose, uma vez que contaminam águas e pastagens com oocistos eliminados nas fezes (Mainar et al. 1996, Van Der Puije et al. 2000), cuja ingestão é a principal via de transmissão para os herbívoros, como, por exemplo, os ovinos e os caprinos (Engeland et al. 1996).

Em humanos, a toxoplasmose é considerada uma das enfermidades parasitárias mais comuns do mundo (Tonelli 2000), e uma importante fonte de infecção são os caprinos infectados por T. gondii. A doença pode se dar pelo consumo de carne crua ou malcozida e de leite in natura, procedentes de animais contaminados (Dubey 1980, 1996, Sacks et al. 1982, Chiari \& Neves 1984, Skinner et al. 1990, Vitor et al. 1991, Luft \& Remington 1992, Figueiredo et al. 2001).

Sendo assim, o presente estudo teve como objetivos: (a) estimar as freqüências de caprinos soropositivos a $T$. gondi, no estado de São Paulo, pela reação de imunofluorescência indireta (RIFI); (b) mapear os focos - uma propriedade com pelo menos um animal infectado (Mossero 2008, comunicação pessoal), por meio do Sistema de Informações Geográficas (SIG); (c) verificar possíveis associações entre positividade do agente e faixa etária, sexo, ocorrência de problemas reprodutivos (abortamentos, natimortalidade e nascimento de filhotes fracos e prematuros) e presença de gatos, nas propriedades; (d) verifi- car o risco de infecção para a saúde pública por meio da comercialização de carne e leite.

\section{MATERIAL E MÉTODOS}

Foram colhidas amostras de sangue de 923 caprinos, de ambos os sexos (51 machos e 872 fêmeas), com idade acima de 3 meses, distribuídos em três faixas etárias: <1 ano (181), 1-4 anos (618) e >4 anos (124). Os animais eram provenientes de 17 propriedades voltadas para a produção de leite com manejo intensivo, localizadas em diferentes municípios do estado de São Paulo (Fig.1). Os soros obtidos foram mantidos a $-20^{\circ} \mathrm{C}$, até a realização do diagnóstico.

Durante o período das colheitas de sangue, foi aplicado um inquérito sobre saúde, para levantamento epidemiológico relacionado à presença de gatos, problemas reprodutivos (abortamentos, natimortalidade e nascimento de filhotes fracos e prematuros) e comercialização de carne e leite de origem caprina.

As amostras de soros foram avaliadas pela reação de imunofluorescência indireta (RIFI), utilizando-se conjugado antiIgG específico para caprinos, marcado com o isotiocianato de fluoresceína. O exame foi conduzido segundo o método descrito por Camargo (1974). Consideraram-se positivas as amostras com título igual ou superior a 1:16.

O estudo da freqüência de ocorrência de Toxoplasma gondii, nas propriedades, foi realizado considerando-se os limites de intervalo de $95 \%$ de confiança para a proporção de positividade. As associações entre essa ocorrência e os respectivos dados epidemiológicos sobre localização do capril, sexo e idade e, também, falhas reprodutivas e presença de gatos, nas propriedades, foram verificadas pelo teste de associação de Goodman para contrastes entre populações multinomiais (Goodman 1964, 1965). Todas as discussões foram realizadas no nível de $5 \%$ de significância.

A visualização da distribuição geográfica dos capris e das freqüências de anticorpos anti- $T$. gondii foi feita por meio da aplicação do Sistema de Informações Geográficas (SIG), IDRISI32 (Eastman 1999).

\section{RESULTADOS}

Dos 923 soros obtidos, 216 foram positivos para anticorpos anti-T. gondii (RIFI ${ }^{316}$ ), com freqüência percentual de ocorrência de $23,40 \%$, tendo os limites de confiança estimados em $20,67 \%-26,13 \%$.

Os resultados apresentados no Quadro 1 mostram diferenças significativas nas ocorrências de soropositividade de caprinos a Toxoplasma gondii, entre as propriedades. Das 17 estudadas, foram encontrados 15 focos de $T$. gondii, com freqüências de positividade variando de $2,70 \%$ a $81,25 \%$.

Os resultados das associações da RIFI com as variáveis sexo, faixa etária, gatos no capril e falhas reprodutivas são apresentados no Quadro 2.

Não se verificou diferença na freqüência de ocorrência de anticorpos anti- $T$. gondii conforme o sexo dos caprinos $(P>0,05)$. No que se refere à faixa etária, a ocorrência de positividade foi significativamente maior $(P<0,005)$ nos animais com idade entre um e quatro anos e maior de quatro anos. Foi observada associação signi- 
Quadro 1. Distribuição de freqüência da positividade de anticorpos anti-Toxoplasma gondii, pela reação de imunofluorescência indireta $(\geq 16)$, por propriedade

\begin{tabular}{cccccc}
\hline $\begin{array}{c}\text { Proprie- } \\
\text { dade }\end{array}$ & Município & $\begin{array}{c}\text { Presença } \\
\text { de gatos }\end{array}$ & $\begin{array}{c}\text { Total de } \\
\text { animais } \\
\text { estudados }\end{array}$ & $\begin{array}{c}\text { № de } \\
\text { animais } \\
\text { positivos }\end{array}$ & $\begin{array}{c}\text { Animais } \\
\text { positivos } \\
(\%)\end{array}$ \\
\hline 1 & Serra Negra & Sim & 128 & 8 & 6,25 \\
2 & Araçoiaba da Serra & Sim & 63 & 6 & 9,52 \\
3 & Itapetininga & Não & 78 & 4 & 5,13 \\
4 & Batatais & Sim & 106 & 24 & 22,64 \\
5 & Jaboticabal & Sim & 75 & 9 & 12,00 \\
6 & Piedade & Não & 37 & 1 & 2,70 \\
7 & Cotia & Sim & 37 & 5 & 13,51 \\
8 & São Paulo & Sim & 78 & 61 & 78,20 \\
9 & Mogi-Guaçu & Sim & 70 & 48 & 68,57 \\
10 & Monteiro Lobato & Não & 25 & 0 & 0,00 \\
11 & Piquete & Sim & 16 & 13 & 81,25 \\
12 & São J. dos Campos & Sim & 43 & 18 & 41,86 \\
13 & Pirassununga & Sim & 59 & 2 & 3,39 \\
14 & Lençóis Paulista & Sim & 33 & 6 & 18,18 \\
15 & São Seb. da Grama & Sim & 29 & 6 & 20,69 \\
16 & Pardinho & Não & 21 & 0 & 0,00 \\
17 & Botucatu & Sim & 25 & 5 & 20,00 \\
Total & & & 923 & 216 & 23,40
\end{tabular}

Quadro 2. Distribuição de freqüência de anticorpos antiToxoplasma gondii, em caprinos do estado de São Paulo, pela reação de imunofluorescência indireta $(\geq 16)$, segundo sexo, faixa etária, presença de gatos e falhas reprodutivas

\begin{tabular}{lcccc}
\hline Variável & $\begin{array}{c}\text { Total de } \\
\text { animais }\end{array}$ & $\begin{array}{c}N^{\circ} \text { de } \\
\text { animais } \\
\text { positivos }\end{array}$ & $\begin{array}{c}\text { Freqüência } \\
\text { relativa } \\
(\%)\end{array}$ & $\mathrm{P}$ - valor \\
\hline $\begin{array}{l}\text { S Sexo } \\
\text { Macho }\end{array}$ & 51 & 14 & 27,5 & $\mathrm{P}>0,05$ \\
$\quad$ Fêmea & 872 & 202 & 23,2 & \\
Faixa etária & 181 & 19 & 10,5 & $\mathrm{P}<0,05$ \\
$\quad$ 1 ano & 618 & 164 & 26,5 & \\
$\quad$ 1-4 anos & 124 & 33 & 26,6 & \\
$\quad$ 4 anos & & & & \\
Gatos no capril & 762 & 211 & 27,7 & $\mathrm{P}<0,05$ \\
$\quad$ Presença & 161 & 5 & 3,1 & \\
$\quad$ Ausência & & & & \\
Falhas reprodutivas & 592 & 140 & 23,9 & $\mathrm{P}>0,05$ \\
$\quad$ Sim & 331 & 76 & 23,1 & \\
Não & & & &
\end{tabular}

ficativa $(P<0,05)$ entre a presença de gatos e a existência de caprinos soropositivos para o microrganismo, ou seja, presença de gatos, nos capris, promoveu elevação da ocorrência de positividade. Não houve associação significativa $(P>0,05)$ entre positividade dos anticorpos e ocorrência de falhas reprodutivas.

As Figuras 1 e 2 ilustram, respectivamente, a freqüência de positividade de caprinos soropositivos a $T$. gondii e os tipos de comercialização de produtos de origem caprina realizada pelas propriedades, de acordo com as localizações dos capris estudados. A sua observação conjunta demonstra que há diversas relações entre freqüência de infecção e comercialização, havendo animais positivos tanto em propriedades que comercializavam leite pasteurizado e "in natura" como naquelas de exploração mista.

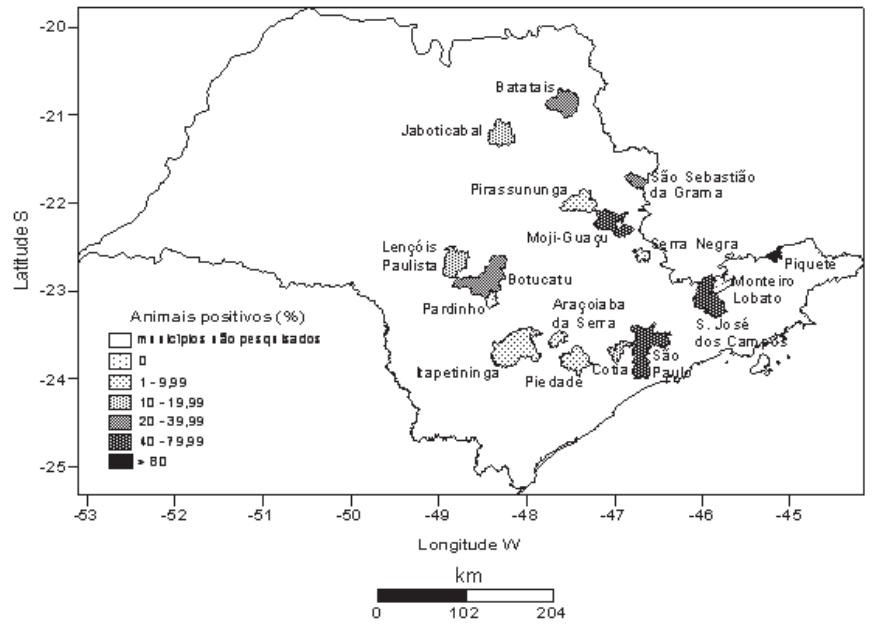

Fig.1. Freqüência de caprinos soropositivos a Toxoplasma gondii, conforme a localização dos capris.

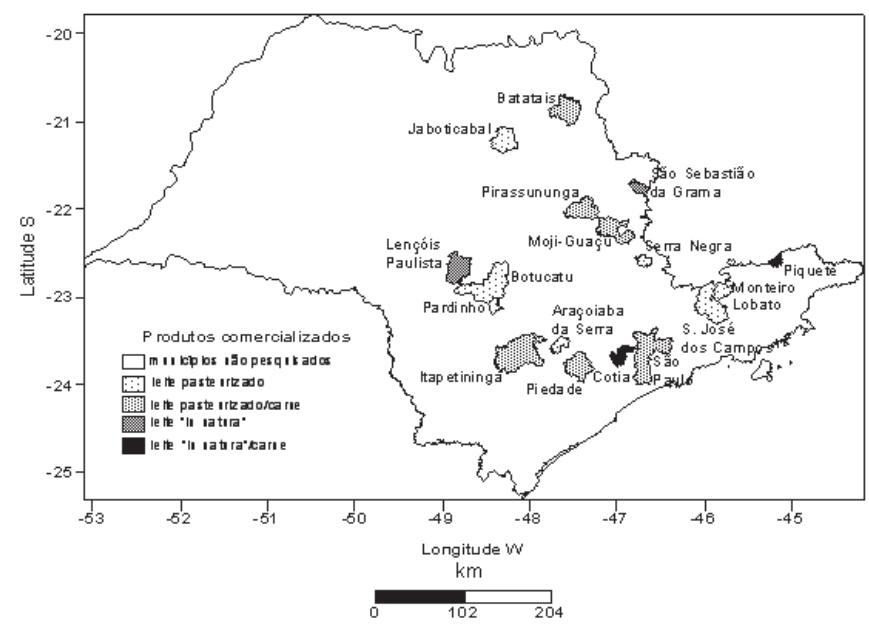

Fig.2. Tipos de comercialização de produtos de origem caprina realizada pelas propriedades.

\section{DISCUSSÃO E CONCLUSÕES}

O conhecimento da ocorrência e da epidemiologia de enfermidades infecto-contagiosas é de fundamental importância para o planejamento de saúde dos animais, e a utilização de mapas tem contribuído para se visualizar a distribuição geográfica e se formularem hipóteses sobre os fatores de risco (Mayer 1983). Os SIGs representam a possibilidade de aplicação de um importante instrumento no estudo das associações e das inter-relações entre localização e ambiente e ocorrência da doença, possibilitando, dessa forma, o acesso à transformação e à atualização dos dados de forma interativa.

No caso da toxoplasmose em caprinos, isso significa uma grande contribuição, uma vez que o rebanho caprino do estado de São Paulo está aumentando (FAO 2005), e essa doença pode comprometer, gravemente, a saúde dos animais e dos seres humanos.

A freqüência de anticorpos anti- T. gondii de $23,40 \%$ (RIFI $\geq 16)$, encontrada no presente estudo, foi superior à 
relatada por Mainard et al. (2003) e Meireles et al. (2003), que obtiveram $17 \%$ de soropositividade pelo ELISA e $14,5 \%$ pela RIFI (16), respectivamente, também no estado de São Paulo. Por outro lado, Figliuolo et al. (2004) verificaram soropositividade de $28,68 \%$ pela RIFI (64).

Em outros estados brasileiros e em várias regiões do mundo, foram encontrados valores semelhantes aos aqui relatados (Ruppanner et al. 1978, Dubey 1985, Dubey \& Adams 1990), superiores (Chiari et al. 1987, Machado \& Lima 1987, Opel et al. 1991, Sella et al. 1994, Silva et al. 2003) e, mesmo, inferiores (Araújo et al. 1984, Samad et al. 1997, Nieto \& Melendez 1998, Figueiredo et al. 2001).

É importante salientar que a variação de técnicas de diagnóstico e diferentes pontos de corte utilizados pelos autores dificultam a comparação de valores de soroprevalência. De qualquer modo, independentemente dos testes e critérios, verifica-se, por este estudo, que a toxoplasmose também se encontra difundida nos capris do estado de São Paulo.

As freqüências percentuais de positividade observadas nos capris estudados (Quadro 1) mostram grande variação na ocorrência de anticorpos anti- $T$. gondii (de $0 \%$ a $81,25 \%$ ), semelhante ao obtido por Figliuolo et al. (2004), com variação de positividade de 3,34\% a $100 \%$.

No que se refere ao sexo dos caprinos, não foi verificado nenhum tipo de associação (Quadro 2), semelhante aos resultados obtidos por Machado \& Lima (1987) e Sella et al. (1994). Por outro lado, Silva et al. (2003) encontraram uma porcentagem de fêmeas sororreagentes significativamente maior que a de machos: $43,88 \%$ contra $21,21 \%$. Já Dubey \& Adams (1990) verificaram maior porcentagem de machos soropositivos a $T$. gondii, embora tenham concluído que o número de machos estudados foi pequeno, para que se pudessem fazer comparações.

Quanto à idade dos animais (Quadro 2), observou-se uma associação positiva entre o aumento da faixa etária e a positividade de anticorpos, o que ocorreu, provavelmente, pela maior chance de exposição dos caprinos ao agente. Chegaram a semelhante constatação Machado \& Lima (1987), Dubey \& Adams (1990), Opel et al. (1991), Sella et al. (1994), Nieto \& Melendez (1998), Figueiredo et al. (2001) e Figliuolo et al. (2004).

A ocorrência de falhas reprodutivas, nos capris estudados, não esteve associada à positividade de anticorpos anti- $T$. gondii, o que está de acordo com Opel et al. (1991), que encontraram títulos maiores que 64 para $T$. gondii em 185 soros de caprinos sem sinais clínicos, na Nova Zelândia. Resultados semelhantes também foram obtidos por Machado \& Lima (1987) e Silva et al. (2003), que verificaram, em caprinos e ovinos, porcentagem de sororreação menor nos grupos em que houve perdas reprodutivas.

Na presente pesquisa, constatou-se importante associação entre a presença de gatos, nos capris, e a ocorrência de anticorpos anti- T. gondii (Quadro 2). Nas propriedades onde foi relatada a presença de hospedeiros definitivos, a variação na freqüência de animais positivos ao T. gondii foi de 3,39\% a $81,25 \%$ (Quadro 1); onde não houve esse tipo de relato, a variação foi de $0 \%$ a 5,13\%. Resultados diferentes foram verificados por Figliuolo (2003), posto que, em capris sem presença de gatos, o autor encontrou positividade variando de $20 \%$ a $60 \%$.

Apesar da baixa freqüência de animais positivos a $T$. gondii, nos capris sem gatos, os números devem ser considerados, pois, além dos oocistos liberados com as fezes dos felídeos, que contaminam água e pastagens, existe a possibilidade de transmissão de $T$. gondii de outras formas infectantes (Chiari et al. 1987, Vitor et al. 1991). Diante do perigo da toxoplasmose caprina para a saúde pública, uma vez que o consumo de leite cru ou carne crua ou malcozida de animais infectados constitui fonte potencial de transmissão de toxoplasmose para o homem (Dubey 1996, Bonametti et al. 1997, Sibley 2003), a investigação sobre a comercialização de produtos de origem caprina, a partir de capris contaminados, pode oferecer subsídios sobre o risco substancial para a população.

A apresentação geográfica dos dados representa um ganho considerável na eficiência da interpretação epidemiológica dos resultados. A gradação na intensidade das hachuras revela, neste estudo, aumento de agravos à saúde. Além disso, a análise conjunta dos dois mapas (Fig.1 e 2) permite uma identificação mais fidedigna das ocorrências e distribuições geográficas com maiores fatores de risco tanto para a saúde animal como para a saúde pública.

Ainda, as análises conjuntas dos dados geográficos das Figuras 1 e 2 revelam que podem ou não existir diferentes fatores de risco de infecção para o homem.

Embora houvesse propriedades sem animais soropositivos para $T$. gondii e que somente comercializavam leite pasteurizado, observaram-se, focos com elevada freqüência de ocorrência de anticorpos anti- $T$. gondii, onde se comercializavam leite "in natura" e/ou carne de caprinos, os quais, se contaminados, constituiriam importantes fontes de infecção aos seus consumidores.

\section{REFERÊNCIAS}

Araújo F.A.P., Silva N.R.S., Chaplin E.L. \& Santos E.B. 1984. Prevalência de anticorpos toxoplásmicos em soros de caprinos da região da grande Porto Alegre/RS. Arq. Fac. Vet. UFRGS 12:35-40.

Bonametti A.M., Passos J.N., Silva E.M.K. \& Bortoliero A.L. 1997. Surto de toxoplasmose aguda transmitida através da ingestão de carne crua de gado ovino. Revta Soc. Bras. Med. Trop. 30:21-25.

Camargo M.E. 1974. Introdução às técnicas de imunofluorescência. Revta Bras. Patol. Clin. 10:143-169.

Chiari C.A. \& Neves D.P. 1984. Toxoplasmose humana adquirida através da ingestão de leite de cabra. Mem. Inst. Oswaldo Cruz 79:337340.

Chiari C.A., Lima W.S., Lima J.D. \& Antunes C.M.F. 1987. Soro-epidemiologia da Toxoplasmose caprina em Minas Gerais, Brasil. Arq. Bras. Med. Vet. Zootec. 39:587-609.

Dubey J.P. 1980. Persistence of encysted Toxoplasma gondii in caprine livers and public health significance of toxoplasmosis in goats. J. Am. Vet. Med. Assoc. 177:1203-1207. 
Dubey J.P. 1985. Serologic prevalence of toxoplasmosis in cattle, sheep, goats, pigs, bison, and elk in Montana. J. Am. Vet. Med. Assoc. 186:969-970.

Dubey J.P. 1996. Strategies to reduce transmission of Toxoplasma gondii to animals and humans. Vet. Parasitol. 64:65-70.

Dubey J.P. \& Adams D.S. 1990. Prevalence of Toxoplasma gondii antibodies in dairy goats from 1982 to 1984 . J. Am. Vet. Med. Assoc. 196:295-296.

Dubey J.P. \& Kirkbride C.A. 1989. Enzootic toxoplasmosis in sheep in north-central United States. J. Parasitol. 75:673-676.

Eastman J.R. 1999. IDRISI: a grid-based geographic analysis system. $32^{\text {th }}$ ed. Clark University Graduate School of Geography, Worcester.

Engeland I.V., Waldeland H., Kindahl H., Ropstad E. \& Andresen O. 1996. Effect of Toxoplasma gondii infection on the development of pregnancy and on endocrine foetal - placental function in the goat. Vet. Parasitol. 67:61-74.

FAO. 2005. Statistical database. FAO, Rome. http://apps.fao.org/page/ collections?subset=agriculture.

Figliuolo L.P.C. 2003. Prevalência de anticorpos anti-T. gondii (Nicolle e Manceaux, 1909) e Neospora caninum Dubey, Carpenter, Speer, Topper e Uggla, 1998, em ovinos e caprinos do estado de São Paulo. Dissertação de Mestrado, Faculdade de Medicina Veterinária e Zootecnia, Universidade de São Paulo, São Paulo, SP. 90p.

Figliuolo L.P., Rodrigues A.A.R., Viana R.B., Aguiar D.M., Kasai N. \& Gennari S.M. 2004. Prevalence of anti-Toxoplasma gondii and antiNeospora caninum antibodies in goat from São Paulo State, Brazil. Small Ruminant Res. 55:29-32.

Figueiredo J.F., Silva D.A.O., Cabral D.D. \& Mineo J.R. 2001. Seroprevalence of Toxoplasma gondii infection in goats by the indirect haemaglutination, immunofluorescence and immunoenzymatic tests in the region of Uberlândia, Brazil. Mem. Inst. Osvaldo Cruz 96:687-692.

Goodman L.A. 1964. Simultaneous confidence intervals for contrasts among multinomial populations. Ann. Math. Stat. 35:716-725.

Goodman L.A. 1965. On simultaneous confidence intervals for multinomial proportions. Technometrics 9:247-254.

Luft B.J. \& Remington J.S. 1992. Toxoplasmic encephalitis in AIDS. Clin. Infect. Dis. 15:211-222.

Machado T.M.M. \& Lima J.D. 1987. Freqüência de anticorpos anti-Toxoplasma gondii em caprinos criados sob diferentes formas de exploração no estado de Minas Gerais. Arq. Bras. Med. Vet. Zootec. 55:485487.

Mainar R.C., De La Cruz C., Asensio A., Domingues L., Vazquez-Boland J.A. 1996. Prevalence of agglutinating antibodies to Toxoplasma gondii in small ruminants of the Madri Region, Spain, and identification of factors influencing seropositivity by multivariate analysis. Vet. Res. Commun. 20:153-159.
Mainardi R.S., Modolo J.R., Stachissini A.V.M., Padovani C.R. \& Langoni H. 2003. Soroprevalência de Toxoplasma gondii em rebanhos caprinos no Estado de São Paulo. Revta Soc. Bras. Med. Trop. 136:759761.

Mayer J.D. 1983. The role of spatial analysis and geographic data in the detection of disease causation. Soc. Sci. Med. 17:1213-1221.

Meireles L.R., Galisteo Junior A.J. \& Andrade Junior F. 2003. Serological survey of antibodies to Toxoplasma gondii in food animals from São Paulo state, Brazil. Braz. J. Vet. Res. Anim. Sci. 40:267-271.

Nieto S.O. \& Melendez R.D. 1998. Seroprevalence of Toxoplasma gondii in goats from arid zones of Venezuela. J. Parasitol. 84:190-191.

Opel U., Charleston W.A.G., Pomroy W.E. \& Rommel M.A. 1991. A survey of the prevalence of Toxoplasma infection in goats in New Zealand and a comparison of the latex agglutination and indirect fluorescence tests. Vet. Parasitol. 40:181-186.

Ruppanner R., Riemann H.P. \& Farver T.B. 1978. Prevalence of Coxiella burnetti ( $Q$ fever) and Toxoplasma gondii among dairy goats in California. Am. J. Vet. Res. 39:867-870.

Sacks J.J., Roberto R.R. \& Brooks N.F. 1982. Toxoplasmosis infection associated with raw goat's milk. J. Am. Med. Assoc. 248:1728-1732.

Samad M.A., Dey B.C., Chowdhury N.S., Akhtar S. \& Khan M.R. 1997. Sero-epidemiological studies on Toxoplasma gondii infection in man and animals in Bangladesh. Southwest Asian J. Trop. Med. Public Health 28:339-343.

Sella M.Z., Navarro I.T., Vidotto O., Freire R.L. \& Shida P.N. 1994. Epidemiologia da Toxoplasmose caprina: levantamento sorológico do Toxoplasma gondii em caprinos leiteiros na microregião de Londrina, Paraná, Brasil. Revta Bras. Parasitol. Vet. 3:13.

Sibley L.D. 2003. Recent origins among ancient parasites. Vet. Parasitol. 115:185-198.

Silva A.V., Cunha E.L.P., Meireles L.R., Gottschalk S., Mota R.A. \& Langoni H. 2003. Toxoplasmose em ovinos e caprinos: estudo soroepidemiológico em duas regiões do Estado de Pernambuco, Brasil. Ciência Rural 33:115-119.

Skinner L.J., Timperly A.C. \& Wightman D. 1990. Simultaneous diagnosis of toxoplasmosis in goats and goatowner's family. Scand. J. Infect. Dis. 22:359-361

Tonelli E. 2000. Toxoplasmose, p.1327-1339. In: __ (Ed.), Doenças Infecciosas na Infância e na Adolescência. $2^{2}$ ed. Medsi, Rio de Janeiro.

Van Der Puije W.N.A., Bosompem K.M., Canacoo E.A., Wastling J.M. \& Akanmori B.D. 2000. The prevalence of anti-Toxoplasma gondii antibodies in Ghanaian sheep and goats. Acta Trop. 76:21-26.

Vitor R.W.A., Pinto, J.B. \& Chiari C.A. 1991. Eliminação de Toxoplasma gondii através de urina, saliva e leite de caprinos experimentalmente infectados. Arq. Bras. Med. Vet. Zootec. 43:147-154. 